\title{
MANIFESTAÇÕES PÚBLICAS E PRIVADAS: IDEIAS, AÇÕES, EXPRESSÕES E O CASO "ROLEZINHO"
}

\section{Lucas Catib de Laurentiis Correio ${ }^{1}$}

\section{Resumo}

Os conflitos gerados pelo exercício do direito de reunião passaram a ser corriqueiros. E eles não se restringem mais à simples questão de se a ocupação de espaços públicos por manifestantes causa embaraços à circulação de automóveis ou pessoas. Com a proliferação de insatisfações e a facilidade da comunicação dos organizadores dos eventos com os manifestantes, os problemas se tornaram mais complexos. Problemas que são agravados quando tais ideias e insatisfações são expressadas em um ambiente urbano, em que a mobilidade de pessoas é dificultada e o choque de interesses, corriqueiro. Saber como, em quais condições, em que locais, enfim, quais os contornos do direito fundamental à livre manifestação e reunião é, por isso, uma tarefa não só interessante, mas também urgente. O trabalho propõe uma discussão desses aspectos sob um enfoque jurídico, sem afastar possíveis pontos de contato com outras áreas de conhecimento.

Palavras chave: direito de manifestação e reunião; direitos fundamentais; direito constitucional.

\section{I.}

Brasil, 15 de março de 2015. Mais de um milhão de pessoas marcharam por ruas, praças e avenidas. Foi a maior manifestação popular desde o movimento das "diretas já". Os objetivos eram variados. Manifestantes das mais diversas idades e classes protestavam contra a corrupção sistêmica, abusos do governo, a alta carga tributária, exigiam a deposição da presidente em exercício e, em alguns casos, o retorno da ditadura militar. Estados Unidos da América, 14 de abril de 2015. Duzentas pessoas marcharam pelas ruas de Baltimore em protesto contra a violência policial que vitimou Freddie Gray, de 25 anos, um afrodescendente que estava sob custódia policial. Trinta e quatro pessoas foram presas e dois policiais, feridos. Incidentes e manifestações semelhantes ocorreram em Nova Iorque, após a morte do também afro-americano Eric Garner, de 43 anos, que foi espancado até a morte por policiais e, no ano anterior, quando Michael Brown, de 18 anos, foi morto a tiros por um policial no condado de Ferguson, Missouri. Acusado perante o Tribunal do Júri deste estado, o agente Darren Wilson foi absolvido. Moscou, 30 de maio de 2015. Sem apresentar justificativas, a prefeitura proibiu a realização de marcha pacífica denominada Gay Pride. Os ativistas que insistiram em protestar foram espancados e dispersados. Jerusalém, 30 de

\footnotetext{
${ }^{1}$ Doutor em direito constitucional. E-mail: lucaslaurentiis@terra.com.br
} 
julho de 2015. Yishaï Shlissel, um judeu ortodoxo, esfaqueou seis pessoas durante a passeata do orgulho gay. Uma delas, adolescente de 16 anos, faleceu dois dias depois. O agressor havia cumprido dez anos de prisão em decorrência de agressões semelhantes ocorridas em 2005. Ele foi liberado duas semanas antes do ataque.

Manifestar é um ato extremo, que por isso mesmo é regulado com dificuldade pelo Direito. A forma rígida da norma, seus contornos e limites, dificilmente e raramente se alinham perfeitamente ao fato narrado. Afinal, qual é o limite do uso da força policial que enfrenta manifestações violentas? Quais limites podem ser impostos às diversas formas de ação e reação dos manifestantes? Eles podem marchar e ocupar toda e qualquer via ou espaço, ou seu protesto deve ser limitado e comprimido a locais em que o interesse de terceiros, alheios à manifestação, não sejam afetados? Enfim e mais importante, para o direito constitucional, o que é uma manifestação legítima?

Pretendo responder algumas dessas perguntas. Para isso, apresentarei os esboços de um conceito constitucional do direito à livre manifestação (II) para, em seguida formular nossas respostas aos conflitos mais corriqueiros envolvendo o exercício de tal direito fundamental (III). Enfim, proponho uma reflexão crítica com base em um caso recente, julgado pelo Superior Tribunal de Justiça (IV). O objetivo é fornecer subsídios para o debate e análise jurídicos de um direito de alta importância para a realização de ideais democráticos elementares, mas que raramente é abordado e tematizado com o rigor analítico e a atenção merecidos.

II.

O direito comparado oferece elementos para a definição do direito constitucional à liberdade de manifestação e reunião. Em Castor-Transport e Love-Parade, ${ }^{3}$ o Tribunal Constitucional Alemão definiu o âmbito de proteção da liberdade de reunião como o pessoas que, buscando um objetivo comum, participem do debate público de ideias relevantes para a sociedade. Objetivo comum quer dizer aquele que não pode ser exercido de forma independente, por cada um dos participantes. O conjunto de torcedores de um evento esportivo, o conjunto de pessoas que pretendam assistir a um filme, ou os espectadores de um concerto, ${ }^{4}$ apesar de serem um conjunto de pessoas, que dividem o mesmo espaço, não são considerados participantes de uma reunião no sentido constitucional. Falta a todos eles o elemento comum e indivisível que une a ação dos participantes. Mas os torcedores que pretendam não só assistir a uma partida, mas também se manifestar contra as más condições dos estádios e os espectadores de cinemas ou peças de teatro, que ao se dirigirem ao espetáculo pretendam defender uma causa política e social, deixam a posição passiva e passam a agir ativamente e de forma

\footnotetext{
${ }^{2} B \operatorname{VerfGE}$, NJW 2002, 1031.

${ }^{3} B$ VerfGE, NJW 2001, 2459.

${ }^{4}$ Schlink, Bernhard/Pieroth, Bodo, Staatsrecht II: Grundrecht, 26. Auf., Heidelberg, C.F. Müller, 2010, p. 185.
} 
conjunta. Se isso ocorre, haverá uma reunião protegida constitucionalmente. ${ }^{5}$

Em Fraport, o Tribunal alemão foi além. Em sua visão, não importa mais se esse debate ocorre em espaços públicos, como uma praça ou rua, ou em espaços de domínio privado, como, no caso, o aeroporto de Frankfurt, que é gerido por uma sociedade de economia mista. Decisivo é se tal debate ocorre ou não. ${ }^{6} \mathrm{~A}$ justificativa de tal limitação é a proteção especial conferida ao direito de reunião em relação à liberdade de expressão (art. 5, GG) e liberdade geral de ação (art. 2ª GG). E a diferença específica e a razão da proteção especial da liberdade de reunião se encontra, na visão do Tribunal, na correlação desse direito fundamental com o exercício e realização de uma forma de democracia participativa. ${ }^{7}$ Reuniões que simplesmente expressem tradições populares, ou festas em que os participantes somente pretendam se divertir, cantando, dançando ou ouvindo músicas, mesmo que essas sejam expressão de uma forma de cultura ou contracultura, não são consideradas manifestações do direito de reunião (visão restritiva do direito de reunião).

De forma similar, mas analisando os contornos do direito de reunião sob a ótica da Constituição brasileira de 1969, Celso de Mello sustentou que o conceito de tal direito fundamental tem cinco elementos. São eles: o elemento pessoal, pois não há reunião de uma só pessoa; o temporal, já que a manifestação não pode ser perpétua; o intencional, pois os participantes devem procurar um objetivo comum; o espacial, vez que a reunião deve ocorrer em locais delimitados e, enfim, o elemento formal, pois a reunião pressuporia, ao ver desse autor, a organização dos participantes, o que pressupõe a existência de alguma espécie de direção entre eles. ${ }^{8}$

Mas tal qual apresentadas, tais condicionantes são insuficientes ou incorretas. Afirmar, como se faz na primeira condicionante, que para existir reunião deve haver uma pluralidade de participantes, é dizer o obvio, sem responder o questionamento principal: afinal, qual o número de participantes exigido para que essa proteção constitucional tenha incidência? No direito Alemão, uma solução foi encontrada em uma interpretação analógica: uma vez que o Código Civil (BGB, $\$ 57$ e $\$ 73$ ) exige um número mínimo de três pessoas para a criação de uma associação, o mesmo requisito poderia ser exigido para a incidência da proteção constitucional à liberdade de manifestação. ${ }^{9}$ Duas razões afastam tal analogia do contexto brasileiro. Primeiro, a previsão constitucional que assegura a liberdade de associação contém previsão ampla, que não limita o número mínimo de possíveis participantes da demonstração pública: "todos podem reunir-se". Segundo, desde a aprovação da Lei 12.441 de 2011, não se exige nem mesmo a pluralidade de sujeitos para a constituição de sociedade empresária de responsabilidade limitada. Seria um contrassenso impor à manifestação pública de ideias um requisito mais rígido

\footnotetext{
${ }^{5}$ Sachs, Michael, Verfassungsrecht II: Grundrechte, 2. Auf., Berlin, Springer, 2003, p. 359.

${ }^{6} B \operatorname{VerfGE} 128,226$.

${ }^{7}$ Hoffmann-Riem, "Neuere Rechtsprechung des BVerfG zur Versammlungsfreiheit", NVwZ, 2003, p. 259. Na jurisprudência: BVerfGE, NJW 2002, 1031 (1032).

${ }^{8}$ Mello, Celdo de, "O direito constitucional de reunião", Revista de Jurisprudência do Tribunal de Justiça do Estado de São Paulo, v. 12, no 54 (1978): p. 19-23.
} 
do que o exigido para a constituição de sociedade com fins lucrativos. Basta, portanto, que duas pessoas manifestem ideias em conjunto, para que o direito fundamental à liberdade de reunião tenha incidência. ${ }^{10}$

As condicionantes temporal e intencional são relacionadas, pois se uma pluralidade de sujeitos se reúne, sem prazo determinado para se separarem, haverá uma associação de pessoas, com ou sem fins lucrativos. Não uma manifestação. De toda forma, o requisito intencional tem de ser interpretado de forma ampla, pois os manifestantes podem ter múltiplos objetivos, ou até mesmo um descontentamento difuso frente as condições sociais, econômicas e até culturais de um dado momento histórico. Pode até mesmo ocorrer que, em um primeiro momento, os manifestantes não tenham plena consciência dos objetivos comuns que perseguem. Se no decorrer da demonstração pública, tal elemento surja ou se torne claro, haverá manifestação constitucionalmente protegida.

Disso se infere o problema do requisito formal, que exige das manifestações públicas uma organização estruturada sob um comando central. Mais uma vez, não há indicação de tal requisito no texto constitucional brasileiro. Fora isso, a manifestação pública pode ser o fruto ou a expressão de um descontentamento espontâneo, que prescinde de qualquer organização formal. Enfim, fatos e experiências recentes demonstram que as manifestações públicas hoje são fruto das novas formas de comunicação eletrônica, o que abre na possibilidade não só de existir manifestações sem lideranças previamente determinadas, como também de manifestações ocorrerem no espaço virtual. ${ }^{11}$

Finalmente, há a questão do local em que a reunião é admitida. A esse respeito, em dispositivo linguisticamente interessante, a Constituição autoriza a realização de reuniões em “locais abertos ao público". A expressão indica que não importa se o local da reunião é uma propriedade pública ou privada - esse critério de distinção poderia ser aplicado se a Constituição brasileira dissesse "local aberto e público", mas não é o caso. Na falta de lei que defina o que a expressão constitucional significa, quatro possibilidades devem ser consideradas. $\mathrm{Na}$ primeira, a reunião ocorre em local de propriedade pública e aberto ao público; na segunda, ela é convocada para um local que pertence à Administração Pública, mas fechado ao público; na terceira, a manifestação acontece em local pertencente a particulares, mas aberto ao público; por fim, na quarta hipótese, os manifestantes pretendem se reunir em propriedade particular, fechada ao público.

\footnotetext{
${ }^{9}$ Cf. Schlink, Bernhard/Pieroth, Bodo, Grundrechte Staatsrecht II, p. 186.

${ }^{10}$ Nessa linha: Ipsen, Jörg, Staatsrecht II: Grundrechte, München, Franz Vahlen, 2010, p. 152. A dúvida que poderia surgir a esse respeito é o que diferenciaria a manifestação de duas pessoas é simplesmente de um diálogo ou, no caso de um casal, uma discussão? O problema indica que os requisitos pessoal e intencional tem relação estreita e, quanto menores forem as exigências no que diz respeito à quantidade de participantes de uma manifestação, maiores deverão ser os requisitos e as limitações impostas ao objetivo comum perseguido pelos manifestantes. Em sentido semelhante, criticando a noção ampla do conceito de manifestação: Hoffmann-Riem, Wolfgang, "Versammlungsfreiheit", in: Merten, Detlef/ Papier, Hans-Jürgen, Handbuch der Grundrechte, Heidelberg, C.F. Müller Verlag, Bd. 4, 2006, p. 1041.

${ }^{11} \mathrm{O}$ movimento Anonymous é exemplo concreto desse fato.
} 
As duas primeiras situações são resolvidas pela legislação administrativa. Bens públicos de uso comum do povo - praças e avenidas, por exemplo - são, por definição, abertos ao público. A manifestação nessas localidades está autorizada. Já prédios que pertençam à Administração Pública, mas onde o acesso seja restrito aos funcionários públicos, são localidades em que a manifestação é proibida. A sede de uma Prefeitura se enquadra nessa classe de bens. Por outro lado, a sede do Poder Legislativo é um caso especial em que o local de trabalho do funcionário público tem a característica de ser necessariamente aberto ao público. Isso porque, por definição, Parlamento é o local destinado à expressão e ao debate público de ideias. Não há como proibir a realização de manifestações convocadas para essas localidades.

As situações mais problemáticas ocorrem quando a reunião ocorre em local aberto ao público de propriedade privada. Como distinguir esses espaços e os locais privados fechados ao público, onde a liberdade de reunião não pode ser exercida? Uma vez que a legislação civil brasileira não define a figura do "bem particular aberto ao público", ${ }^{12}$ devemos buscar critérios e indicações no próprio texto constitucional. Uma possível diferenciação pode ser desenvolvida com a análise da concorrência entre os direitos à liberdade de reunião e inviolabilidade de domicílio. A legislação civil e a jurisprudência brasileiras seguem uma interpretação ampliativa do direito à inviolabilidade domiciliar: não só o local de residência particular, mas também o local de trabalho são locais protegidos por força da incidência do direito fundamental à inviolabilidade do domićilio. ${ }^{13}$

E em abstrato, a incidência dessa proteção constitucional (inviolabilidade do domić́lio) afasta o direito à liberdade de reunião. Só quando as características específicas e concretas do local de trabalho indicarem a necessidade de inversão dessa presunção é que poderá ser admitida a reunião em locais privados.

O movimento grevista que ocupa uma agência bancária em manifestação por melhores salários é um exemplo. Aqui a ação estatal não deve proibir a reunião, mas também não pode autorizar que o exercício desse direito se torne uma causa impeditiva do direito ao trabalho e à profissão. Nesses casos, dois parâmetros devem guiar nossa avaliação. Em nível abstrato, as figuras da proporcionalidade e da proibição de excessos oferecem parâmetros para a aferição concreta da legitimidade da restrição ao direito fundamental afetado: a ação estatal deve ser suficiente para resguardar o direito ao trabalho, sem anular a liberdade de profissão. Em concreto isso quer dizer que se deve preservar tanto quanto possível a difusão das ideias defendidas pelos manifestantes, sem deixar que isso impeça o exercício da liberdade de profissão. Penso, por isso, que seria possível exigir que os manifestantes deem passagem a quem pretenda exercer sua profissão, o que também não compromete a mensagem difundida pelos manifestantes.

Já os casos que envolvem a ocupação de centros privados de compras, ou a manifestação em locais de

\footnotetext{
${ }^{12} \mathrm{O}$ art. 98 do Código Civil brasileiro se contenta com a distinção entre bens públicos e particulares.

${ }^{13}$ Nesse sentido, cf. os arts. 70 e 72 do Código Civil e o julgamento do Mandado de Segurança 23.595/DF, relator Ministro Celso de Melo, publicado no Informativo de Jurisprudência 185/2000.
} 
domínio público cuja administração tenha sido concedida à iniciativa privada, ${ }^{14}$ por exemplo, contêm uma especificidade que faz presumir a legitimidade da reunião convocada para ocorrer em seu interior: em ambos os casos, a atividade privada pressupõe a circulação do público no local de domínio privado. A abertura desses centros à convivência de pessoas com interesses e ideais democráticos diversos é elemento essencial e inseparável da própria atividade do titular do bem privado. Voltarei a esse tema na quarta parte.

\section{III.}

O direito à manifestação e exercício da democracia são elementos inseparáveis. Por isso mesmo, a regulação dessa relação é um exercício constante, que exige reflexão jurídica e debate social sérios. Não há razão para se espantar que muitas questões estejam em aberto. No Brasil, o ciclo de manifestações iniciado em junho de 2013 trouxe várias dessas questões ao debate público. O que é uma manifestação pacífica? Manifestantes podem vestir máscaras ou vestimentas de guerra? A reunião pode ocorrer em espaços públicos e privados? Minha intensão é aqui apresentar algumas respostas a esses questionamentos.

Pacífica é a manifestação não beligerante e não armada. A reunião proibida constitucionalmente é, portanto, aquela que apresenta, concomitantemente, um elemento intencional (subjetivo) e um elemento de fato (objetivo), que, conjugados, apresentem grave potencial de dano a direitos de terceiros. ${ }^{15}$ Se a manifestação foi organizada com a intenção de lesar, destruir, causar danos ou dilapidar bens públicos ou privados, existe o elemento subjetivo da proibição constitucional. Mas só a intenção de lesar não é suficiente se os manifestantes não dispõem de meios materiais suficientes para tanto. Por isso, é preciso que a manifestação seja "armada”. Ou seja, os meios empregados pelos manifestantes devem ser idôneos para realizar a lesão intencionada. Para a proibição legítima do direito à reunião, não é suficiente constatar que "objetos" foram arremessados pelos manifestantes. Se esses "objetos" forem rosas, penas, ovos ou tomates, não há potencial lesivo suficiente que justifique a dissolução da manifestação. Isso quer dizer que uma interpretação demasiadamente ampla do termo "pacífico", que exclua do âmbito de proteção do direito de reunião toda e qualquer possibilidade de lesão, equivale a uma negação desse direito

Mas isso não quer dizer que a pessoa que eventualmente se sinta lesada com o arremesso desses objetos esteja completamente desamparada. Ela poderá pleitear em juízo o ressarcimento de eventuais danos que vier a sofrer - uma camisa manchada ou dissolução da reunião. A conclusão contrária simplesmente impossibilitaria todo o tipo de manifestação satírica e o happening, que são expressões de descontentamentos legítimos, que invariavelmente causam inconvenientes. A vida em democracia nem sempre é completamente agradável a todos e

\footnotetext{
${ }^{14}$ Foi a situação enfrentada pelo Tribunal Constitucional Alemão em Fraport (BVerfGE 128, 226).

${ }^{15}$ Uma análise semelhante é encontrada em: Sachs, Michael, Verfassungsrecht II: Grundrechte, p. 358.
} 
aceitar esse fato é o primeiro passo para a construção de uma convivência realmente pacífica.

Outra questão relevante e pouco debatida na literatura brasileira é a definição do termo "arma" (art. 5, XVI, da Constituição Federal de 1988). A reunião proibida é aquela em que todos os manifestantes portam armas? E o porte de armas permitido pela legislação também pode servir de fundamento para a dissolução de uma manifestação? Quanto à primeira questão, três situações devem ser consideradas. Na primeira, todos os participantes da reunião portam armas. $\mathrm{Na}$ segunda, só uma pequena parte deles tem o porte. Finalmente, na terceira hipótese, a pequena parte porta a arma, mas a grande maioria dos participantes sabe e apoia essa atitude. As primeiras situações são mais fáceis: a primeira reunião é proibida; a segunda, permitida. A terceira hipótese é complexa e exige mais cuidado. A chave para sua solução está na observação do elemento subjetivo, ou intencional, do direito de reunião: se os demais participantes apoiam o porte da arma e sabem que ele tem a finalidade de ferir ou prejudicar terceiros ou participantes da reunião, tal manifestação deve ser proibida. Ao contrário, se os demais manifestantes sabem que pessoas armadas participam da manifestação, mas não consideram a possibilidade de tais armas serem utilizadas para ferir ou causar danos, essa reunião deve ser permitida. Decisivo para a admissibilidade da dissolução da reunião é a intenção e a beligerância do todo ou da maior parte dos participantes. Se a agressividade vem de uma pequena parte deles, não é possível proibir a reunião. Nesse caso, a solução é impedir a manifestação daqueles que insistam em portar armas, não a dissolução da manifestação.

Questão diversa, mas relacionada, está na possibilidade de os participantes da manifestação usarem máscaras ou panos que escondam o rosto. ${ }^{16} \mathrm{O}$ elemento distintivo para a proibição do uso dessas vestimentas deve mais uma vez ser a intenção beligerante dos manifestantes. Máscaras que ironizem governantes são comuns e representam uma forma legítima de manifestação de pensamento. O mesmo vale para máscaras que estejam relacionadas a orientações religiosas. Por isso, penso que restringir, em abstrato, a expressão de crenças e ideias dos manifestantes é um ato desprovido de autorização constitucional. A Constituição assegura a inviolabilidade de crença e religião, o que seria suficiente para afastar qualquer possibilidade de controle sobre a vestimenta de fundo

\footnotetext{
${ }^{16}$ A polêmica a esse respeito é grande no Brasil. O Estado do Rio de Janeiro, por exemplo, editou a Lei no 6.528 , de 11 de setembro de 2013, que, em seu art. 30, inciso IV, e $\$ 3^{\circ}$, prevê: "Art. $3^{\circ}$ - O direito constitucional à reunião pública para manifestação de pensamento será exercido: [...] IV - sem o uso de máscaras nem de quaisquer peças que cubram o rosto do cidadão ou dificultem sua identificação; [...] $\int 3^{\circ}-\mathrm{A}$ vedação de que trata o inciso IV do caput deste artigo não se aplica às manifestações culturais estabelecidas no calendário oficial do Estado”.

A Assembleia Legislativa do Estado de São Paulo, no dia 3 de julho de 2014, também aprovou lei proibindo o uso de mascaras em protestos. Dito projeto foi sancionado pelo Governador do Estado no dia 29 de agosto de 2014. Convertida em Lei (n. $15.556 / 2014)$, a proibição tem a seguinte redação: “Art. $2^{\circ}$ - Na manifestação e reunião a que se refere o artigo $1^{\circ}$, com o objetivo de assegurar que ninguém a faça no anonimato, fica proibido o uso de máscara ou qualquer outro paramento que possa ocultar o rosto da pessoa, ou que dificulte ou impeça a sua identificação. Parágrafo único - A proibição a que se refere o "caput" deste artigo não se aplica às manifestações e reuniões culturais incluídas no calendário oficial do Estado”.

No interior do Estado de São Paulo, decisões judiciais proibiram o uso de máscaras por manifestantes. Também surgiram, em alguns municípios, como Campinas, propostas de lei para a proibição completa dessas condutas. A proposta enviada pelo
} 
religioso (Burcas ou Niqabs, por exemplo) utilizada por manifestantes. Aliás, há um forte potencial discriminador na atitude do governante ou juiz que autoriza que manifestantes se vistam de uma forma e não de outra. Penso também que essa conclusão não é afastada pelo inciso IV do artigo $5^{\circ}$, da Constituição de 1988, que assegura a expressão de pensamento, mas veda o anonimato. ${ }^{17}$ Primeiro porque não há reunião anônima: os manifestantes querem visibilidade para suas ideias e ocupam espaços públicos ou privados com essa intenção. Se o objetivo fosse o anonimato, ficariam em casa. Segundo porque, se um oficial de polícia verificar a necessidade de identificar algum dos manifestantes, basta que exija sua identificação civil. Só na falta desta, será o manifestante submetido à identificação criminal. ${ }^{18}$ Tudo isso independe de o manifestante vestir ou não máscaras.

Finalmente, se alguns manifestantes não querem ver seu rosto exposto em meios de comunicação, mas querem expressar seu descontentamento ou indignação, o uso de máscaras se torna forma de exercício do direito de personalidade e imagem. Exigir que o manifestante se exponha da maneira pretendida pelo Estado é uma violação a esses direitos fundamentais. Só há uma hipótese em que a utilização de máscaras em manifestações é constitucionalmente proibida: se a vestimenta indicar a realização de um ato de caráter paramilitar. Quando for comprovado que, ao utilizarem máscaras, os manifestantes indicam a intenção comum de praticar atos de vandalismo, será admitida a proibição da vestimenta. $\mathrm{O}$ ônus da prova recai aqui sobre a Administração Pública. ${ }^{19}$ E na dúvida, a máscara utilizada pelos manifestantes deve ser permitida.

IV.

Itaquera, São Paulo. 7 de dezembro de 2013. Em uma região de recente expansão e desenvolvimento imobiliários, que decorreram do recente crescimento econômico e dos investimentos realizados no local para a realização da Copa do Mundo de 2014, jovens de 14 a 17 se encontraram em um shopping center para ouvir funk, dançar e paquerar. Surgia o "rolezinho". ${ }^{20}$ Outros encontros foram marcados, via de regra por meio de redes sociais, nas mais diversas localidades. As reações foram imediatas. Amedrontados, os centros de compras foram à Justiça e, em um primeiro momento, essas conseguiram liminares que impediram os encontros. Essas decisões

\footnotetext{
Ministério da Justiça para regulamentar o direito à liberdade de reunião foi na mesma linha.

${ }^{17}$ Em sentido contrário, conferir o editorial da Folha de São Paulo, intitulado Equívoco Mascarado, publicado no dia 15 de julho de 2014, e o artigo de Beatriz Horbach na edição de 6 de julho de 2013 do Observatório da justiça constitucional, disponível em: http://www.conjur.com.br/2013-jul-06/observatorio-constitucional-restringir-manifestacoes-nao-inconstitucional (acesso no dia 19 de março de 2014).

${ }^{18}$ Conferir, nesse sentido, o art. 5, LVIII, Constituição Federal de 1988: “o civilmente identificado não será submetido a identificação criminal, salvo nas hipóteses previstas em lei”.

${ }^{19}$ Hoffmann-Riem, Neuere Rechtsprechung, p. 264.

20 Sobre a origem e razões desse fenômeno, ver a seguinte matéria jornalística: http://epoca.globo.com/vida/noticia/2014/01/origem-bdo-rolezinhob.html (acesso no dia 17 de agosto de 2015).
} 
foram em sua maioria cassadas pelo Tribunal de Justiça do Estado de São Paulo. ${ }^{21}$ Indignados, os participantes dos "rolezinhos" e seus defensores apontaram para o potencial efeito discriminatório das medidas restritivas e para a falta de opções de lazer disponíveis para os habitantes de regiões mais pobres. ${ }^{22}$ Sem sucesso, afinal passado mais de um ano das primeiras decisões judiciais a esse respeito, ainda não há uma orientação firme acerca da legitimidade constitucional desses atos. Prova disso são as recentes decisões em que magistrados proíbem a entrada de adolescentes em centros de compras, não mais com base no argumento de que a reunião deles pode lesar o patrimônio particular, mas agora sob o pretexto da defesa da integridade física dos próprios manifestantes.

"Algazarras, tumultos e correrias potencializam o risco de acidentes graves com crianças que frequentam shopping centers", é o que diz a portaria de Paulo César Gentille, juiz de direito em Ribeirão Preto que proibiu a entrada de adolescentes menores de dezesseis anos em dois shoppings da região. ${ }^{23}$ Contestada perante o Tribunal de Justiça de São Paulo, tal medida foi referendada sob o argumento de que aglomerações em espaços fechados trazem riscos à integridade dos jovens e adolescentes que lá circulam. Contra tal decisão foi impetrado novo habeas corpus, desta vez no Superior Tribunal de Justiça, pela Defensoria Pública do Estado de São Paulo. ${ }^{24}$ Relator dessa última demanda, o ministro Luís Felipe Salomão reconheceu o problema formal de tal impetração, pois a jurisprudência não admite a impugnação via habeas corpus de decisão denegatória de liminar, mas concedeu a ordem considerando a possibilidade da análise ex officio do pleito deduzido.

No mérito, dois argumentos fundamentaram a procedência do pedido. Primeiro, no Estatuto da Criança e Adolescente (ECA) não há expressa previsão da possibilidade de uma portaria regular a entrada de crianças ou adolescentes em shoppings centers. ${ }^{25}$ Segundo, a medida em questão é desproporcional, pois, em vez de impedir a entrada de jovens com idade inferior a 15 anos, os centros comerciais poderiam demandar a concessão de liminares que impedissem os encontros caso a caso. Como a restrição abstrata da liberdade de manifestação é mais intensa do que a aquela que é aferida em concreto, a conclusão a que se chega é que a medida restritiva contida na portaria era desnecessária. ${ }^{26} \mathrm{Já}$ com relação à desproporção em sentido estrito de referida intervenção,

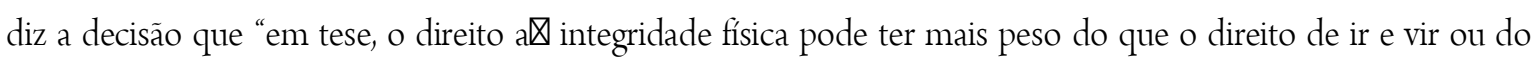

\footnotetext{
${ }^{21} \mathrm{O}$ índice de êxito dos pedidos liminares foi de 58\%. O Tribunal de Justiça cassou $100 \%$ de tais decisões. Para a análise quantitativa de tais demandas no Estado de São Paulo, ver: Severi, Fabiana Cristina; Frizzarim, Nickole Sanchez; Borges, Saulo Simon. O perfil dos processos judiciais sobre os rolezinhos em São Paulo, in: Severi, Faiana Cristina. Dossiê Rolezinho: Shopping Centers e violação de direitos humanos no Estado de São Paulo, Ribeirão Preto: Faculdade de Direito de Ribeirão Preto/USP, 2015, p. 9 e ss. ${ }^{22}$ Para uma defesa desse ponto de vista, ver o artigo de Tatiana Ivanovici, publicado no painel tendências e debates da Folha de São Paulo, no dia 18 de janeiro de 2014. Texto disponível em: http:/ /wwwl.folha.uol.com.br/opiniao/2014/01/1399092-rolezinhosem-shoppings-devem-ser-coibidos-nao.shtml (acesso no dia 05 de setembro de 2015).

${ }^{23}$ Citação da exposição de motivos da portaria n. 1, de 2015, editada em resposta à representação da associação de lojistas de Ribeirão Preto no dia 20 de março de 2015.

${ }^{24}$ Trata-se do HC 320.938-SP, rel. Ministro Luís Felipe Salomão, j. 5 de junho de 2015.

${ }^{25} \mathrm{O}$ fundamento de tal conclusão é encontrado do artigo 149 do ECA, que apresenta os casos em que se admite a regulação, via portaria, da liberdade de ir e vir de jovens e adolescentes.
} 
direito ao lazer. Contudo, no caso dos autos, o impedimento a\ entrada e permanência de crianças e adolescentes em centros comerciais não evita eventuais danos $\mathrm{a} \rrbracket$ integridade física dos menores. Pelo contrário, se os pais não podem acompanha $\mathbb{X}$-los, estes ficarão nas ruas ou parques - expondo-se a riscos ainda maiores - ou ficarão em casa privados do convívio com outras crianças e adolescentes e do lazer". ${ }^{27}$

Tenho que deixar claro que sou simpático à causa dos rolezinhos e penso que, hoje, esse é sim uma configuração legítima e espontânea do direito de manifestação. Ou seja, em princípio, concordo com o resultado da decisão do Superior Tribunal de Justiça. Mas acho também que esse é um tema que ainda precisa ser estudado pelo direito e por outras disciplinas com mais cautela. E também pressinto que, da forma como foram analisadas por tal decisão, as características e peculiaridades dessa manifestação social se tornaram ainda mais confusas. Por isso, aqui meu objetivo não é contestar a legitimidade dos 'rolezinhos' e sim avaliar essa decisão do STJ, para que, quem sabe, no futuro, tenhamos um debate mais sério e coerente a esse respeito. Vamos, então, aos pontos críticos dessa decisão.

Inexistem os pressupostos processuais para o conhecimento da matéria debatida no processo em questão. Primeiro porque o habeas corpus é ação de conhecimento que não admite dilação probatória. ${ }^{28} \mathrm{Sem}$ tal possibilidade, não há que se falar em opções mais ou menos restritivas do direito fundamental em questão. Nessa via não é possível analisar a necessidade de medidas alternativas do ato estatal interventivo. Não é tudo, pois mesmo que se admitisse a análise de medidas alternativas em habeas corpus, o Superior Tribunal de Justiça não é uma Corte constitucional e, por isso, não pode analisar a constitucionalidade de leis ou atos normativos quando essa questão for o tema principal da demanda. No caso em questão é exatamente isso o que ocorre, pois nele se diz que a portaria do juiz que impede a entrada de jovens em centros comerciais ofende a proporcionalidade e esta nada mais é do que um instrumento de defesa de direitos fundamentais contra intervenções excessivas do Estado. ${ }^{29}$ Falar que a proporcionalidade foi desrespeitada equivale, portanto, a dizer que o direito fundamental afetado foi restringido em excesso. E isso é uma questão eminentemente constitucional.

Esses problemas poderiam ter sido evitados se a decisão do Superior Tribunal de Justiça se restringisse a avaliar a legalidade da medida em questão. Uma vez que se considere que ela tem amparo no dispositivo (artigo 149) do ECA que autoriza juízes a regularem, via portaria, o direito de ir e vir de crianças e adolescentes, ela seria uma medida válida. Caso contrário, ela seria uma medida ilegal, não por ser desproporcional, mas sim porque a

\footnotetext{
${ }^{26}$ Nessa linha e apresentando outros critérios para a classificação das intervenções em direitos fundamentais: Clérico, Laura. El examen de proporcionalidad en el Derecho constitucional, Buenos Aires: Eudeba, 2009, p. 116 e ss.

${ }^{27}$ STJ, decisão monocrática, HC n. 320.938-SP, rel. Ministro Luís Felipe Salomão, j. 5 de junho de 2015.

${ }^{28}$ Nessa linha, na literatura: Grinover, Ada Pelegrini; Gomes Filho, Antônio Magalhães Gomes; Fernandes, Antônio Scarance. Recursos no processo penal, $4^{a}$ ed. São Paulo: Revista dos Tribunais, 2005, p. 350. Em sede jurisprudencial: STF, HC 117.173-DF, relator Min. Luiz Fux, j. 18 de fevereiro de 2014.

${ }^{29}$ Nessa linha, por muitos: Reimer, Phillipp. ... und Macht zu Jüngern alle Volker? Von universellen Verfassungsprinzipien und Weltmission der Prinzipientheorie der Grundrechte, Der Staat 52 (2013): 27-57, p. 31.
} 
autoridade que a criou não tem competência para tanto. Por isso mesmo, é contraditório argumentar ao mesmo tempo, como faz a decisão em questão, que o juiz não tinha competência para editar tal portaria e que, além disso, tal ato é desproporcional. Para que a intensidade restritiva de uma medida estatal seja avaliada há que se pressupor necessariamente que tal ato exista para o direito. Mas se o ato é desde o início inválido, por faltar a ele um dos pressupostos formais para sua produção, não tem sentido analisar seus efeitos em relação aos direitos fundamentais afetados. Afinal, para o direito, tais efeitos simplesmente não existem.

Enfim, na própria análise do último dos testes que compõem a proporcionalidade, há problemas, pois, a esse respeito, diz a decisão que "[e]m tese, o direito à integridade física pode ter mais peso do que o direito de ir e vir ou do direito ao lazer. Contudo, no caso dos autos, o impedimento à entrada e permanência de crianças e adolescentes em centros comerciais não evita eventuais danos à integridade física dos menores. Pelo contrário, se os pais não podem acompanhá-los, estes ficarão nas ruas ou parques - expondo-se a riscos ainda maiores - ou ficarão em casa privados do convívio com outras crianças e adolescentes e do lazer". Ora, se é assim, a medida restritiva em questão não atinge a finalidade por ela mesma proposta - evitar possíveis danos ou lesões à integridade física de crianças e adolescentes - e, nesse sentido, ela é uma medida inadequada à finalidade almejada. Não há espaço para se falar, portanto, em necessidade, e muito menos, como paradoxalmente faz a decisão, em proporcionalidade em sentido estrito da medida restritiva em questão.

Em meio a tais confusões, as questões elementares que deveriam ser objeto de apreciação dogmática e jurisprudencial permanecem não solucionadas: afinal, o que é o "rolezinho"? O que pretendem os jovens que dele participam? Enfim, há nesse caso um exercício do direito de manifestação? Sem responder a essas questões, não tem sentido discutir se os centros de compra são espaços privados equivalentes a praças públicas. ${ }^{30} \mathrm{Afinal}$, como já foi aqui observado, a Constituição de 1988 não leva em consideração a titularidade ou a natureza do espaço em que se realiza a manifestação. Não importa, portanto, se a área em que se realiza a manifestação é pública ou privada. Decisivo é saber se o local é ou não aberto ao público, o que não se discute no caso dos shopping centers. Como nem mesmo essas questões foram debatidas, não se sabe ao certo se a medida restritiva em questão afeta o direito de ir e vir ou o direito de reunião e manifestação de crianças e adolescentes. ${ }^{31}$ Essa é a carência dogmática mais grave não só dessa decisão, mas de todo o debate até agora desenvolvido a esse respeito, que se caracteriza pela troca de acusações entre defensores e opositores dos "rolezinhos" e análises sociológicas dos integrantes desse movimento. Falta saber o que ele significa para o direito. Hoje pende de julgamento no Supremo Tribunal Federal

\footnotetext{
${ }^{30}$ Defendendo a tese, que parece não ter amparo no que dispõe o artigo 98 do Código Civil ("São públicos os bens do domínio nacional pertencentes às pessoas jurídicas de direito público interno; todos os outros são particulares, seja qual for a pessoa a que pertencerem") de que os shopping centers passaram a fazer as vezes não só de praças públicas, mas também de parques públicos e até ruas: Conci, Luiz Guilherme Arcaro. Da praça pública à praça de alimentação - Problemas derivados da relação entre os direitos fundamentais de propriedade, liberdade de expressão e reunião em Shopping Centers, RBECn. 10 (2009): 67-95.

${ }^{31}$ Esse tema demandaria um estudo específico, que não é objeto do presente artigo, como já mencionamos.
} 
o HC 129.633-SP, a ser relatado pelo ministro Luís Roberto Barroso. Esses temas serão discutidos e analisados ou o "rolezinho" permanecerá em um limbo jurídico, social e dogmático?

\title{
OBSERVAÇÕES FINAIS
}

Meu proposito aqui foi apresentar diferentes questões e perspectivas do direito constitucional de reunião. Foram expostos alguns exemplos, problemas, dificuldades e suas possíveis soluções. As características teóricas também foram abordadas no decorrer da exposição. Gostaria agora de me concentrar na característica mais elementar desse direito: sua função política e social. Em países de passado autoritário o direito de reunião tem um valor especial. Neles todos sabem que a ditadura se alimenta do controle da consciência e expressão. E sabem que impedir o exercício do direito de reunião é uma das formas mais perversas desse controle. Por isso, é preciso ter muita muita cautela ao analisar os limites, constitucionais ou legais, do direito de manifestação pacífica. Mas isso não quer dizer que esses sejam pontos, ou direitos, intocáveis ou não regulamentáveis. Ao contrário, é preciso debater, pesquisar, julgar e decidir. Regular, discutir e, se for o caso, refazer a regulamentação do direito à reunião. Aprender com os erros e não tapar os ouvidos para a crítica. É exatamente isso o que nos ensina o direito de manifestação e reunião: nada nem ninguém está imune a críticas ou a descontentamentos. Todos estão sujeitos ao debate e ao juízo público. Para o direito à reunião nada nem ninguém é um tema tabu. Mas acima de tudo, o direito à reunião também nos ensina a sermos mais humanos e tolerantes, pois não nos aproxima de quem tem as mesmas ideias, mas também nos força a aceitar quem pensa de outra forma.

\section{PUBLIC AND PRIVATE MANIFESTATIONS: IDEAS, ACTIONS, EXPRESSIONS AND THE CASE "ROLEZINHO”}

\begin{abstract}
Conflict generated by the exercise of the right do assemble have become commonplace. They are no longer restricted to the simple question of whether the occupation of public spaces by protesters cause embarrassment to the movement of vehicles or people. With the proliferation of dissatisfaction and the ease of communication between events organizers and protesters, the problems have become more complex. Problems that are exacerbated when such ideas and dissatisfaction are expressed in an urban environment, in which people mobility is hampered and the clash of interests, everyday. Know how, under what conditions, in which local, in short, which outlines the fundamental right to free expression and assembly is therefore a task not only interesting, but also urgent. The work proposes a discussion of these aspects under a legal approach, without alienating potential points of contact with other areas of knowledge.
\end{abstract}

Keywords: right to demonstrate and assemble; basic rights; constitutional law. 


\section{REFERENCIAS BIBLIOGRÁFICAS}

CONCI, Luiz Guilherme Arcaro. Da praça pública à praça de alimentação - Problemas derivados da relação entre os direitos fundamentais de propriedade, liberdade de expressão e reunião em Shopping Centers, RBEC n. 10 (2009): 67-95.

CLÉRICO, Laura. El examen de proporcionalidad en el Derecho constitucional, Buenos Aires: Eudeba, 2009.

GRINOVER, Ada Pelegrini; GOMES FILHO, Antônio Magalhães Gomes; FERNANDES, Antônio Scarance. Recursos no processo penal, 4a ed. São Paulo: Revista dos Tribunais, 2005.

HOFFMANN-RIEM, Wolfgang, "Versammlungsfreiheit", In: Merten, Detlef/ Papier, Hans-Jürgen, Handbuch der Grundrechte, Heidelberg, C.F. Müller Verlag, Bd. 4, 2006.

"Neuere Rechtsprechung des BVerfG zur Versammlungsfreiheit", NVwZ, 2003, p. 259.

IPSEN, Jörg, Staatsrecht II: Grundrechte, München, Franz Vahlen, 2010.

MELLO, Celdo de, "O direito constitucional de reunião", Revista de Jurisprudência do Tribunal de Justiça do Estado de São Paulo, v. 12, no 54 (1978): p. 19-23.

REIMER, Phillipp. ... und Macht zu Jüngern alle Volker? Von universellen Verfassungsprinzipien und Weltmission der Prinzipientheorie der Grundrechte, Der Staat 52 (2013): 27-57.

SEVERI, Fabiana Cristina; FRIZZARIM, Nickole Sanchez; BORGES, Saulo Simon. O perfil dos processos judiciais sobre os rolezinhos em São Paulo, In: Severi, Faiana Cristina. Dossiê Rolezinho: Shopping Centers e violação de direitos humanos no Estado de São Paulo, Ribeirão Preto: Faculdade de Direito de Ribeirão Preto/USP, 2015.

SACHS, Michael, Verfassungsrecht II: Grundrechte, 2. Auf., Berlin, Springer, 2003.

SCHLINK, Bernhard/PIEROTH, Bodo, Staatsrecht II: Grundrecht, 26. Auf., Heidelberg, C.F. Müller, 2010.

Trabalho enviado em 20 de março de 2016.

Aceito em 16 dejulho de 2016. 